\title{
Os processos de modernização agrícola na região amazônica: transformações recentes na dinâmica produtiva do município de Santarém (Pará)
}

\author{
Marcio Toledo*
}

\section{Resumo}

As políticas de planejamento ao longo dos últimos 50 anos para a Região Amazônica estiveram cunhadas principalmente pelo ideal de sua modernização técnica. Nos anos 1990, o município de Santarém torna-se um "novo front" para a produção de commodities agrícolas no Brasil. A agricultura praticada ali já se inicia com grandes aportes de ciência e tecnologia, e está essencialmente voltada para o mercado internacionalizado. Embora tecnicamente moderno, esse lugar é fragilizado pelos predominantes sistemas de ações instrumentais de um projeto forâneo que desestruturam e desorganizam os sistemas de relações locais.

Palavras-chave: Região Amazônica; Santarém; Modernização agrícola; Uso do território.

The processes of agriculture modernization in the amazon region: recent changes in the dynamics of production of Santarém (Pará)

\section{Abstract}

Planning policies over the past 50 years in the Amazon region were particularly guided by the ideal of technical modernization. In the 1990's, the municipality of Santarém becomes a "new front" for the production of agricultural commodities in Brazil. There the way of producing agricultural

Professor do Departamento de Geociências - Universidade Federal de São João del Rei - CTan (mtoledo@ufsj.edu.br).

Geosul, Florianópolis, v. 26, n. 52, p 77-97, jul./dez. 2011 
TOLEDO, M. Os processos de modernização agrícola na região amazônica:

goods already begins with large inputs of science and technology, and it is mainly focused on the internationalized market. Although technically modern, this place is weakened by the prevailing systems of instrumental actions of a foreign project to disrupt and disorganize the systems of local relations.

Key words: Amazon; Santarém; Agricultural modernization; Use of territory.

\section{A região amazônica}

As políticas de planejamento implementadas ao longo dos últimos 50 anos para a Região Amazônica estiveram cunhadas principalmente pelo ideal de sua modernização técnica. A Região já foi mesmo tratada como um "espaço vazio" a ser ocupado e "integrado ao Brasil" em função de sistemas atividades econômicas da Região Concentrada (Santos \& Silveira, 2001). Compreender os subsistemas de ações de planejamento para esta região é fundamental para entendermos as atuais dinâmicas produtivas no município de Santarém e como o mundo se manifesta em cada lugar, nosso objetivo neste artigo.

O desenvolvimento regional tem constituído os sistemas de ações políticas de Planejamento do Governo brasileiro desde os anos trinta e ganhou novo fôlego após a Segunda Guerra Mundial.

Em 1953, no Governo Getulio Vargas, a Lei de $n^{\circ} 1.806$ determinou a criação da "Amazônia Legal"1 e criou a Superintendência do Plano de Valorização Econômica da Amazônia (SPVEA), primeiro organismo de planejamento e de execução regional brasileiro, que tinha normas mais rígidas a

${ }^{1}$ A Amazônia Legal foi instituída através de dispositivo de Lei para fins de planejamento econômico da região amazônica. Engloba os Estados da Região Norte (Acre, Amazonas, Amapá, Pará, Rondônia, Roraima e Tocantins), e mais o Estado do Mato Grosso (Centro-Oeste), e parte do Maranhão (Nordeste). 
TOLEDO, M. Os processos de modernização agrícola na região amazônica:

seguir através dos planos qüinqüenais, produzidos pela Comissão de Planejamento e aprovados pelo Congresso Nacional. Até que o primeiro desses planos fosse elaborado, a execução do Plano de Valorização Econômica da Amazônia dar-se-ia mediante um "Programa de Emergência" (PE), aprovado no início de 1954 (RAMOS, 2004, p.34). O "Programa de Emergência" estimulava a ocupação baseada na atividade agrícola na Região.

Entre 1948 e 1958, a participação econômica da região em nível nacional caiu de $4,6 \%$ para $4,4 \%$ e não houve aumentos significativos na produção agrícola e praticamente nada foi realizado em relação à colonização. Em relação aos transportes, haviam se iniciado as obras da construção da rodovia BelémBrasília. Em termos de energia, a construção de cinco usinas térmicas e duas hidroelétricas, para atender as demais regiões do país (SPVEA, 1960).

Entre 1964 a 1980, consolidou-se o planejamento Estatal na Região, através de diversos Planos, quer Nacional quer Regional, de Desenvolvimento. Em 1966, como parte do "Plano de Ação Econômica" do Governo Federal, foi lançada a "Operação Amazônia" que apresentava um conjunto de medidas para solucionar, na ótica do Governo Castelo Branco, os problemas da Região, sob a égide do binômio "segurança e desenvolvimento".

As principais ações da "Operação Amazônia" deram suporte ao projeto de ocupação acelerada da Região. Foram modernizados os sistemas normativos das instituições: em 1966, o "Banco de Crédito da Borracha" foi transformado em Banco da Amazônia (BASA), e a SPVEA transformada na "Superintendência de Desenvolvimento da Amazônia" (SUDAM), ambos permanecendo até hoje. Ainda na década de 1960, foi criada a Zona Franca de Manaus, um enclave industrial em meio à economia extrativista e próximo à fronteira norte (Becker, 2001, p. 137; Ramos, 2004, p.38).

A SUDAM, ainda nos anos 1960, foi responsável pela implantação do "Projeto de Pecuarização da Amazônia", uma tentativa de estimular a ocupação da Região, financiada pelo 
TOLEDO, M. Os processos de modernização agrícola na região amazônica:

Governo Federal, como estratégia para viabilizar o acesso à terra por grandes grupos econômicos que já atuavam na Região Concentrada do país.

Em 1973, poucos anos após o lançamento do "Plano de Integração Nacional" (PIN), que previa a construção de uma malha rodoviária complementar aos principais eixos hidroviários, a SUDAM continuava a estimular a prática de atividades pecuárias na Região Amazônica, segundo a superintendência, uma região propícia este sistema de atividades, com excelentes pastagens naturais e espaço amplo para sua expansão (CARVALHO, 1987, p. 183).

Em 1974, foi criado o "Programa de Pólos Agropecuários da Amazônia" (POLAMAZÔNIA), com a finalidade de "promover $o$ aproveitamento integrado das potencialidades agropecuárias, agro-industriais, florestais e minerais, em áreas prioritárias da Amazônia".

Entre os anos de 1981 e 1987 foi implantado o "Programa Integrado da Região Noroeste" (POLONOROESTE), com financiamento do Banco Mundial, para os estados de Rondônia e Mato Grosso. Seus principais objetivos propostos no documento oficial de lançamento eram: o asfaltamento da rodovia BR 364, no trecho Cuiabá - Porto Velho; promover a adequada ocupação demográfica da região noroeste do Brasil, absorvendo populações "economicamente marginalizadas" de outras regiões e proporcionando-lhes emprego; aumentar a produção da região e a renda de sua população; reduzir as disparidades de desenvolvimento intra e inter-regionais; assegurar o crescimento da produção (EMBRAPA, 2009).

Nos anos 1990, as principais ações do "Brasil em Ação" estavam ligadas a recuperação das estradas BR 364 (Brasília-Acre) e BR 163 (Cuiabá-Santarém), ao asfaltamento da BR 174 (Manaus - Boa Vista), a implementação das hidrovias do AraguaiaTocantins e do Madeira, o gasoduto de Urucu e a linha de alta tensão conectando Tucuruí a Altamira e Itaituba (THÉRY, 2005, p.41). 
TOLEDO, M. Os processos de modernização agrícola na região amazônica:

No "Avança Brasil” previa-se a aplicação de cerca de US\$ 43 bilhões, sendo US\$ 20 bilhões para obras em macro-sistema de engenharia para transportes na Amazônia Legal. As ações modernizantes para a Região com o asfaltamento de $7500 \mathrm{~km}$ de rodovias (BR-163 - Cuiabá-Santarém e BR-319 - Manaus-Porto Velho) são realizadas com a intenção de conferir fluidez e também o acesso a áreas remotas da Amazônia.

O principal objetivo dos subsistemas de ações políticas do "Avança Brasil" para a Região Amazônica era viabilizar o uso corporativo e ampliar a fluidez do território, implantando macrosistemas de objetos para transportes e comunicações, ampliando sua eficiência e tornando-a mais competitiva.

Como novo front da produção agrícola modernizada de soja, a Região Amazônica apresentou crescimento, não só em relação ao total produzido mais em relação ao número de estados produtores. Enquanto na safra, 1990/1991 apenas o estado de Rondônia compunha o circuito espacial de produção da soja, na safra 2004/2005, com exceção dos estados do Acre e Amapá todos os demais já faziam parte dele, segundo a CONAB (2009). A quantidade produzida de grãos na Região, que na safra 1990/1991 foi de 5 toneladas subiu para 498 toneladas na safra 2004/2005, e para 562,4 na safra 2007/2008. A quantidade produzida ganhou expressão a partir da safra de 2004/2005 (307 ton.), com o significativo aumento da produção nos estados do Pará (207 ton. contra 7 ton. da safra 2001/2002), Rondônia (227 ton. contra 85 ton. da safra 2001/2002) (CONAB, 2009). A produtividade para a Região Amazônica se elevou entre de 2 ton./ha para 2,8 ton./ha entre as safra 2000/2001 e 2007/2008. Em relação aos estados, na safra 2007/2008, a produtividade no estado do Pará chegou a 2,8 ton./ha e no estado de Rondônia a 3,1 ton./ha. É importante destacar que para a regionalização que adotamos aqui, o estado do Tocantins, que tem expressivo aumento na área plantada, produção e produtividade de soja nos anos 2000, compõe a Região CentroOeste e não a Região Amazônica (SANTOS \& SILVEIRA, 2001, p. LXIV). 
TOLEDO, M. Os processos de modernização agrícola na região amazônica:

Durante os Governos do Presidente Fernando Henrique Cardoso, além os "Eixos Nacionais de Integração e Desenvolvimento", foram criadas duas políticas de grande abrangência na Região Amazônia: o Sistema de Proteção da Amazônia (SIPAM) e o Sistema de Vigilância da Amazônia $(\text { SIVAM })^{2}$, ampliando o conhecimento e o controle sobre o território, agora tecnicamente mais adensado. Apesar de ambos os programas conterem promessas de melhorias nas condições de vida das populações amazônicas, suas dinâmicas revelaram estar em total conformidade e obediência à lógica das grandes corporações transnacionais. Os sistemas de ação do Estado promovem assim um adensamento técnico do meio geográfico amazônico, com sistemas de objetos modernizados, mas indiferentes às legítimas necessidades e demandas da sociedade civil local (LEÃO, 2006, p. 67-68).

No PPA 2004-2007, os projetos previstos continuaram a dar prioridade aos sistemas de engenharia de transportes e energia, desta vez com destaque para hidrovias e ferrovias e com redução dos investimentos previstos para o gasoduto de Urucu. Entre os investimentos diretos do Governo Federal, os mais significativos são da área energética, o desenvolvimento da usina de Tucuruí (R\$ 1814 milhões), a extensão da rede interconectada do Mato Grosso a Rondônia e ao Acre (R\$ 1056 milhões). Em seguida vêm as rodovias: a BR 156, ligando Brasil à Guiana, a BR 230 (Transamazônica), a BR 364, ligando o Rondônia ao Acre e a BR 319, ligando Porto Velho a Manaus, prolongando e facilitando a penetração para o noroeste da Região Amazônica (THÉRY, 2005, p.41).

A maior parte dos projetos implantados ou planejados está ligada a melhoria dos macro-sistemas de engenharia de transportes

${ }^{2}$ O SIPAM/SIVAM é um sistema para controle e defesa do território amazônico, em nome do combate às drogas e preservação do meio ambiente, baseado em moderna tecnologia de radares financiado em 85\% de seu valor de 1,4 bilhões de dólares pelo Eximbank americano (BECKER, 2004). 
TOLEDO, M. Os processos de modernização agrícola na região amazônica:

para escoamento da soja ou a instalação de usinas hidrelétricas que apóiam basicamente a indústria do alumínio na Região Amazônica. A implantação e modernização dos portos, hidrovias, rodovias, ferrovias e hidroelétricas, previstas em todos os PPAs têm buscado dar suporte para a consolidação e expansão do agronegócio na Região Amazônica, viabilizando assim o território nacional como mais um recurso para as grandes tradings comercializadoras da soja produzida na Região Central do Brasil. Essa modernização seletiva é alienadora e fragmentadora.

\section{O mundo no lugar: sistemas de ações modernizantes no município e de Santarém}

$\mathrm{O}$ município de Santarém localiza-se à margem direita do Rio Amazonas no encontro com o Rio Tapajós (numa região conhecida como Baixo Amazonas). Está distante de Belém, capital do estado do Pará, a $780 \mathrm{~km}$ por via aérea, $1876 \mathrm{~km}$ via terrestre e $955 \mathrm{~km}$ via fluvial. Em termos econômicos, é a cidade mais importante do oeste Paraense, contando com uma população de 262.538 habitantes, dos quais 186.297 vivem na área urbana do município (IBGE, 2000).

\section{Mapa 1: Município de Santarém (PA)}

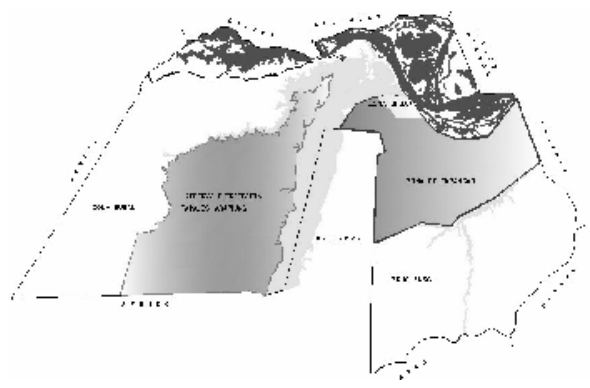

Fonte: Prefeitura Municipal de Santarém, 2008. 
TOLEDO, M. Os processos de modernização agrícola na região amazônica:

Entre os anos 1950 e 2000, houve praticamente uma inversão entre a população rural e urbana no município: a população residente nas áreas urbanas passou de 23,34\% para $71,0 \%$ do total, enquanto na área rural retraiu de $76,66 \%$ para $29 \%$ do total (IBGE, 2000). Os fluxos migratórios também tiveram significativa influência no crescimento populacional, não apenas do município como de toda a região, nas décadas de 1950 e 1960, graças aos estímulos das políticas do Governo Federal para povoar a Amazônia.

Os investimentos em infraestrutura para a cidade foram executados principalmente entre 1969 e 1978, durante a implantação do POLAMAZÔNIA, que levou a cabo algumas obras de saneamento básico.

O processo histórico de formação do município de Santarém pode ser compreendido através de uma análise das diferentes sistemas de atividades econômicas realizadas na região e no município e dos sistemas de ações de planejamento estatal para o local. Para Becker (2001, p.135), a ocupação da Região Amazônica se fez em processos devassadores ligados à valorização momentânea de alguns produtos no mercado internacional, seguidos de longos períodos de estagnação.

No período em que a atividade econômica concentrou-se extração de goma para a fabricação de borracha (1879 a 1912), apesar da pequena produção local, a cidade sofreu um grande processo de modernização técnica por servir de entreposto comercial de grandes quantidades de borracha vindas da região do rio Tapajós e afluentes, abrigando muitos comerciantes em seu centro comercial.

Em torno de cinco décadas, a comercialização da borracha assegurou uma condição semi-monopolista à região na oferta desta matéria-prima fundamental para a expansão da indústria automobilística estado-unidense e européia. A produção de borracha teve seu declínio em 1914, quando os seringais amazônicos passaram a sofrer concorrência dos modernos seringais do sudeste asiático (RAMOS, 2004, p.49). 
TOLEDO, M. Os processos de modernização agrícola na região amazônica:

Com a decadência da produção de borracha, o oeste do estado do Pará acabou mergulhado em uma crise econômica, assim como toda a Região Amazônica. O "fechamento" dos seringais conduziu a uma grande concentração de pessoas ociosas na cidade, a paralisação da frota fluvial e a falta de emprego (AMORIM, 1998, p.175).

Mais tarde, a borracha voltaria a ter significativa importância na economia do município com a implantação de uma moderna indústria e um plantio ordenado de seringueiras da empresa Ford em Santarém, em 1928. As ações desta empresa proporcionaram a criação de novos núcleos urbanos, como Fordlândia e Belterra, em 1926 e 1934, respectivamente. Nestes dois núcleos urbanos funcionavam os principais hospitais da região. Belterra e Fordlândia, já naquele período, dispunham de equipamentos urbanos considerados modernos como uma rede de abastecimento de água com estação de tratamento.

Ao longo do século XX, diferentes atividades econômicas foram desenvolvidas no município de Santarém. Na segunda metade da década de 1930 e início da década de 1940 consolidouse a cultura da juta para atender aos mercados interno e regional de fabricação de sacarias para embalagens de produtos diversos. Instalaram-se fábricas, pequenas indústrias e estabelecimentos comerciais no município (AMORIM, 1998, pp.178-180).

Nos anos 1940, houve um significativo aumento das exportações de madeira (Amorim, 1998, p.176). Destacaram-se nesta década a extração de sementes oleaginosas - o cumarú e castanha-do-pará - cujas exportações saltaram de 30 ton., em 1940, para 70 ton. em 1942. Neste período, a produção de borracha teve a procura internacional ampliada devido a Segunda Guerra Mundial. Com o fim do conflito, a demanda se retraiu novamente.

Nas décadas de 1950 e 1960, a extração de pau-rosa (árvore que produz óleo linalol, usado na indústria de perfumes) possibilitou a instalação de três usinas beneficiadoras em Santarém. A perfumaria Phebo Ltda., fundada em 1932, em Belém (PA) fabricava o sabonete Phebo e cerca de outros duzentos tipos 
TOLEDO, M. Os processos de modernização agrícola na região amazônica:

de perfumes e tinha como componente básico o óleo essencial de pau-rosa (Homma, 2005, p. 2). O sistema de atividades ligadas a exploração do pau-rosa declinou nos anos 1970 em função do aparecimento de um substituto sintético mais barato.

Outra atividade econômica importante para a formação do município, a extração do ouro no vale do rio Tapajós transformou o lugar num grande entreposto comercial de máquinas, equipamentos e alimentos destinado aos garimpos, além de atrair milhares de pessoas para o município. Entre as décadas de 1950 e 1960 verificou-se o maior índice migratório de todo o país em direção a Santarém 52,98\% (AMORIM, 1998, p.99).

A extração aurífera permaneceu até o início da década de 1990, quando os Planos de controle inflacionário promovidos pela equipe econômica da gestão Collor de Mello, no PPA 1991-1995, desvalorizaram o ouro com o confisco dos ativos monetários do país, inviabilizando a garimpagem artesanal no vale do rio tapajós. Nesse período, Santarém e Itaituba (município vizinho), sofreram uma explosão demográfica, pois absorveram grande parte do contingente de garimpeiros que se encontrava embrenhado na floresta (IBGE, 2000).

A diminuição das atividades ligadas à extração de ouro afetou toda a economia municipal: inúmeras lojas de máquinas e equipamentos para garimpo, lojas de compra de ouro (a cidade tinha em torno de cem), lojas de mantimentos, postos de combustíveis e empresas ligadas a aviação fecharam suas portas. Estima-se que, naquele período, o aeroporto de Itaituba tivesse movimentação de pousos e decolagens de pequenos aviões maior do que Congonhas em São Paulo (RAMOS, 2004, p.49).

O sistema de atividades econômicas do município, que estava voltado para o extrativismo, produção rural e ligado a atividades de entreposto comercial, entrou em crise. Além disso, gerou também um grande contingente de desempregados dos garimpos. $\mathrm{O}$ sistema de atividades de garimpo ainda existe no vale do rio Tapajós, porém em menor escala. 
TOLEDO, M. Os processos de modernização agrícola na região amazônica:

Após o Golpe Militar de 1964, Santarém foi considerada "área geograficamente estratégica para a segurança da Amazônia" e declarada, "área de segurança nacional". Seus prefeitos passaram a ser nomeados pelo Governador do estado, que por sua vez era nomeado pelo Presidente da República.

A ocupação mais efetiva da Região Amazônica tornou-se prioridade das políticas de planejamento do Governo Militar. Sob o lema "integrar para não entregar", os militares tiveram papel decisivo na ocupação e urbanização da Região. Os Planos de Governo (1964 - 1984) investiram maciçamente na densificação tecnocientífica do meio geográfico amazônico.

$\mathrm{Na}$ década de 1970, o Governo Federal realizou investimentos nos macro-sistemas de engenharia para circulação no município com a construção de estradas (Santarém-Cuiabá, Transamazônica), de um cais de arrimo, do aeroporto, a pavimentação de vias urbanas, da construção de parte da rede de esgoto sanitário e das galerias pluviais, bem como os projetos de assentamentos populacionais.

Entre meados da década de 1960 e a década de 1980, foi construída a segunda maior hidroelétrica do mundo no município de Santarém, a Hidroelétrica de Curua-uma, com capacidade de geração de 40mw.

A ligação, por via terrestre, com a Região Concentrada do país através da rodovia BR-163 (Santarém-Cuiabá), para os planejadores do Estado militar, seria capaz de promover a integração com a Região Concentrada e o crescimento econômico da Região. As consequiências foram, em grande parte, desastrosas, ampliando a ocupação "desordenada" do território, intensificando os conflitos fundiários e aumentando a concentração de riquezas na região (MACHADO, 1995; BECKER, 1998).

A construção da BR-163 atraiu um grande contingente de pessoas para o lugar, contribuindo com o processo de urbanização da Região. No plano de colonização das margens da rodovia, previa-se a utilização de uma faixa de $100 \mathrm{~km}$ de cada lado, que seria parcelada em projetos de colonização. Os primeiros $10 \mathrm{~km}$ estavam reservados a 
TOLEDO, M. Os processos de modernização agrícola na região amazônica:

pequenos agricultores, em lotes de 100 ha. Além da terra, esses agricultores teriam acesso a crédito, assistência técnica e outros serviços. Os $90 \mathrm{~km}$ restantes seriam vendidos em leilões nacionais a investidores interessados em produção pecuária (CARVALHO, 1987, p.166; RAMOS, 2004, p. 58).

O Governo Militar investiu também na modernização do aeroporto de Santarém. Esse macro-sistema de engenharia para transporte aéreo possui uma pista de $2400 \mathrm{~m}$ de extensão, e é de classe internacional, alternativo a Manaus e Belém, com capacidade para receber grandes aeronaves.

Outra obra de engenharia significativa foi a construção do cais de proteção contra enchentes que se estendeu por $3000 \mathrm{~m}$ pela margem direita do rio Tapajós e diminuiu a incidência de enchentes no município, embora o problema persista.

A construção do Porto de Santarém, também teve início na década de 1970, com o objetivo de melhorar a fluidez das mercadorias produzidas na Região Central do Brasil, aproximandoas do mercado consumidor europeu e norte-americano. O porto é uma importante via de escoamento para produtos agrícolas.

\section{Novas dinâmicas agrícolas no município de Santarém-PA}

Nos anos 1990, Santarém torna-se um "novo front" para a produção de soja e arroz no Brasil. A agricultura que passa a ser praticada ali tem referência planetária e já se inicia com grandes aportes de ciência e tecnologia, além de estar, essencialmente, voltada para o mercado internacionalizado. São extensas áreas de lavouras mecanizadas, utilizando alta tecnologia e grãos selecionados.

A disponibilidade de terras baratas, a proximidade do terminal graneleiro da Cargill, no Porto de Santarém, a existência de extensas áreas passíveis de mecanização, acrescida da disponibilidade de espécies adaptadas para as condições edafo- 
TOLEDO, M. Os processos de modernização agrícola na região amazônica:

climáticas $^{3}$ do lugar favoreceram a expansão da soja para os municípios de Santarém e Belterra. O cultivo da soja teve início na região em meados de 1999 quando foi instalado o terminal graneleiro da Cargill e foram ampliadas as possibilidades de pavimentação da rodovia BR-163. Os produtores agrícolas, vindos na maior parte do Mato Grosso, se instalaram na Região adquirindo terras a baixo custo e iniciaram suas atividades com o cultivo de grãos que podem ser produzidos em rotação com a soja como o sorgo, o milho e o arroz.

Em parceria com outra empresa investidora no circuito espacial produtivo da soja, a Hermasa (do grupo AMaggi), a Cargill tem incentivado a produção de soja na Região Amazônica por meio de apoio tecnológico aos produtores e garantia de compra da produção. A Hermasa, por exemplo, terá um complexo produtor que incluirá usinas de esmagamento de cereais, de produção de ração animal e até um frigorífico para receber a produção de carnes de aves e animais de agricultores terceirizados. O projeto está sendo implantado gradativamente. A Cargill estimula o plantio de soja na região de Santarém, em um raio de até 100 quilômetros do município. A trading financiou, entre 2002 e 2005 o cultivo de 20 mil hectares de soja, que poderiam produzir até 150 mil toneladas por ano (TOLEDO, 2005). Para corrigir o solo amazônico empobrecido de nutrientes, os agricultores recebem, por intermédio da Cargill, calcário de minas do Ceará. A área plantada de soja na safra 2008 foi estimada em 19.500 mil hectares (IBGE, 2009). Técnicos da empresa já detectaram uma área total de mais ou menos 100 mil hectares prontos para serem plantados, em áreas atualmente de pastagens. A área é suficiente para produção de 300 mil toneladas, o que justificaria o empreendimento (TOLEDO, 2005).

Em Santarém, a Cargill tem cerca de 255 produtores cadastrados para compra e venda de soja. Dentre eles, 100 recebem

3 Destaque-se o papel da Embrapa, atuando no circulo espacial de cooperação do circuito espacial produtivo da soja e que desenvolveu cultivares adequadas às condições de solo e clima da região Amazônica. 
TOLEDO, M. Os processos de modernização agrícola na região amazônica:

financiamento para a produção desta cultivar. Em muitas áreas é praticada a rotação entre arroz e soja (FLEXOR et al., 2006, pp.911). Dessa forma, a trading acabou por estimular também o alargamento do circuito espacial produtivo da soja até o município de Santarém.

Como resultado dos incentivos oferecidos pela Cargill, por meio de financiamento da produção agrícola, o perfil do sistema de produção agrícola do município de Santarém tem sofrido transformações. Até 1996, a quantidade produzida de cacau no município era de 2134 toneladas, mas em 1997 essa quantidade caiu para insignificantes 3 toneladas e, atualmente, mantém-se em torno de 4 toneladas, reflexo da maciça entrada da soja no Pará (TOLEDO, 2005; IBGE, 2007).

A área plantada de soja em Santarém, entre 2002 e 2007, aumentou vertiginosamente. Em 2002, soja ocupava apenas 25 hectares e a quantidade produzida era de 600 toneladas. Em 2003, a área plantada passou para 200 hectares. Em 2004, saltou para 4600 ha, em 2005 para 11.000 ha, em 2006 para 22.000 ha, em 2007 para 19.500 quando a quantidade produzida chegou a 58.500 toneladas (IBGE, 2009). Essa expansão do cultivo modernizado nos municípios foi estendida também para os municípios vizinhos como Monte Alegre, Alenquer, Curuá, Prainha e Oriximiná. Já a área produzida de arroz saltou de 4.200 ha em 2000 para 45.000 ha em 2005, com uma queda para 22.140 ha em 2007. As quantidades produzidas foram $6.523,12.300,53.352$ toneladas respectivamente em 2000, 2005 e 2007. 
TOLEDO, M. Os processos de modernização agrícola na região amazônica:

Mapa 2: Área plantada de soja no estado do Pará em 2000

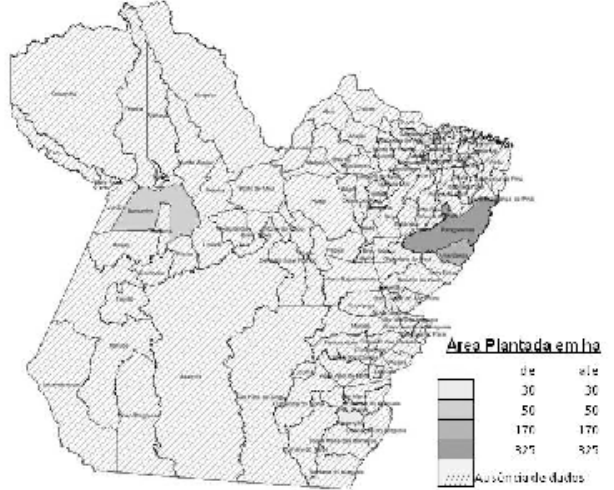

Fonte: PAM - IBGE, 2009. Org.: Márcio Toledo.

Mapa 3: Área Plantada de soja no estado do Pará em 2007

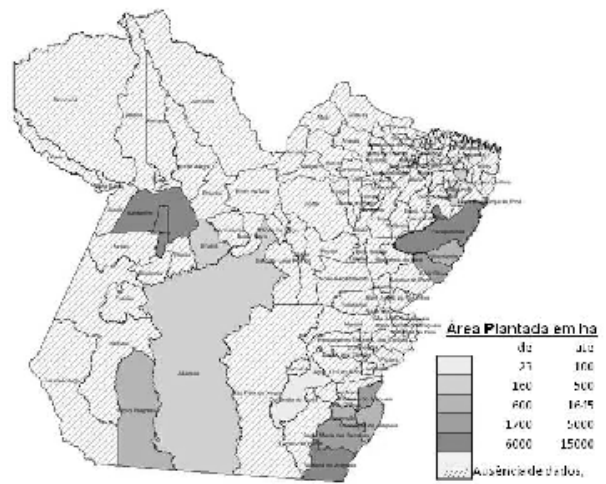

Fonte: PAM - IBGE, 2009. Org.: Márcio Toledo. 
TOLEDO, M. Os processos de modernização agrícola na região amazônica:

Mapa 4: Área Plantada de arroz no estado do Pará em 1990

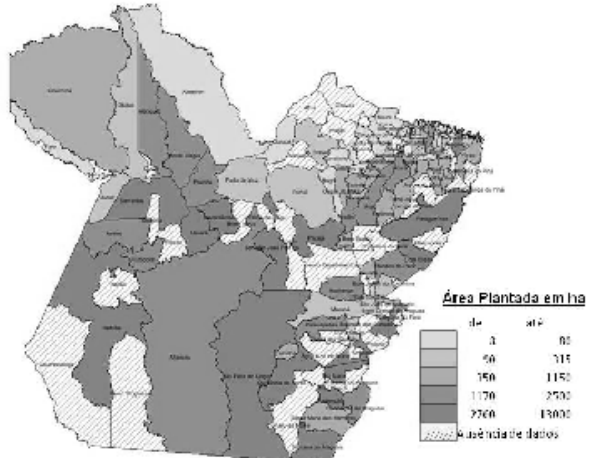

Fonte: PAM - IBGE, 2009. Org.: Márcio Toledo.

Mapa 5: Área Plantada de arroz no estado do Pará em 2007

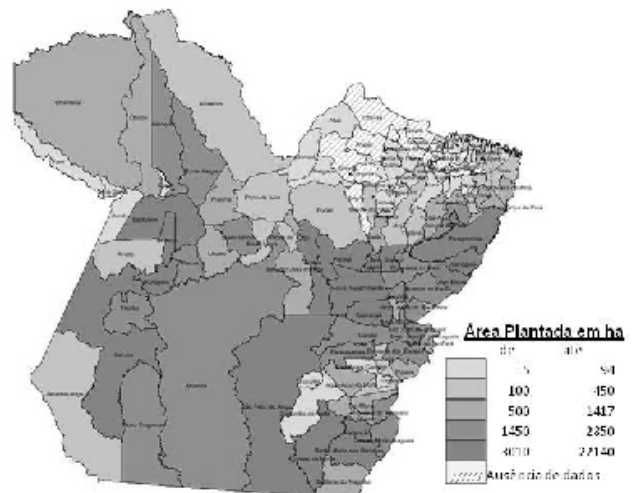

Fonte: PAM - IBGE, 2009. Org.: Márcio Toledo.

O alargamento do meio geográfico com acréscimos de ciência, técnica e informação permitem obter maiores volumes de produtos em áreas mais reduzidas; as possibilidades dadas pelo adensamento da circulação autorizam a especialização produtiva dos lugares, que produzem quase exclusivamente commodities para exportação. 
TOLEDO, M. Os processos de modernização agrícola na região amazônica:

Nas décadas de 1990 e 2000, houve também um importante crescimento comercial na cidade, com a abertura de lojas para venda de equipamentos agrícolas, peças para tratores, conformando e consolidando uma cidade funcional ao agronegócio.

A indústria, no município, praticamente não existe, limitando-se basicamente às de pequeno porte: fábricas de alimentos, construção civil, artefatos de madeira, ou, na maior parte, apenas o beneficiamento de madeira, como matéria-prima para exportação (LEÃO, 2006, p.79).

A consolidação da exportação de grãos pelo Porto de Santarém via asfaltamento da rodovia BR-163, pode promover a inversão do fluxo das cargas que atualmente destinam-se ao Porto de Paranaguá (PR), com o encurtamento de distância em quase 1.000 quilômetros rodoviários e algo em torno de 4.000 quilômetros marítimos. Com isso, os mais de 10 milhões de toneladas de soja produzidas no Mato Grosso podem passar a ser transportados pela rodovia e, em seguida, pelo Porto de Santarém.

\section{Considerações finais}

Aos lugares que compõem o circuito espacial produtivo da soja são exigidos cada vez mais conjuntos de sistemas de objetos técnicos modernizados que viabilizem a manutenção de sua competitividade e assegurem o uso corporativo do território. É desta forma que algumas regiões tornam-se vencedoras da guerra entre os lugares, enquanto a grande maioria dos lugares se vê subjugado e marginalizado. $O$ estabelecimento de redes que buscam apenas cumprir as finalidades pré-determinadas, permite apenas uma eficiência produtiva de parcelas do território nacional, como ferramenta de uso privado de agentes selecionados da economia e da política.

A racionalidade técnica se impõe como projeto para todo o território nacional e manifesta-se nos lugares, mas não beneficia da maior parte da população. A finalidade estritamente econômica que se estabelece produz desarticulações internas no território nacional, 
TOLEDO, M. Os processos de modernização agrícola na região amazônica:

na medida em que são constituídos nexos espaciais essencialmente funcionais, presididos por interesses mercantis e responsáveis por um uso privilegiado dos recursos do território. É sob a invenção da necessidade de viabilização do território para os circuitos produtivos de algumas commodities que se organiza e se instrumentaliza o território nacional.

Manifestando o movimento do mundo, em Santarém (PA), lugar privilegiado dos sistemas de ação das grandes empresas privadas, a agricultura tem sido modernizada. Por meio de Planos Plurianuais, subsistemas de ação política do Estado, aquele ponto do território nacional têm sido viabilizado para uso majoritariamente corporativo.

Ainda que tecnicamente moderno, esse lugar fica fragilizado pelas ações predominantemente técnicas de um projeto forâneo que desestruturam e desorganizam os sistemas de relações locais. A agricultura científica globalizada tem tirado populações que produziam para subsistência de suas terras, o terminal graneleiro da Cargill no Porto de Santarém, deslocou comunidades ribeirinhas. $\mathrm{Na}$ cidade de Santarém, onde se agrupam essas pessoas, os benefícios do "progresso" e do desenvolvimento prometido pelo discurso modernizante que acompanha o alargamento do meio técnico, científico e informacional (agricultura modernizada; porto modernizado) não se concretiza. $\mathrm{O}$ acesso aos direitos sociais como moradia, saúde, educação, saneamento básico ainda são bastante precários naquele lugar. Ao priorizar os investimentos em macrosistemas de engenharia para o uso de empresas privadas, o Estado acaba por deixar de investir em equipamentos sociais. Nesse sentido, o projeto de modernização atual da agricultura tem sido sinônimo de precarização das condições de vida e de trabalho da maioria da população e seu discurso de desenvolvimento não mais que uma falácia. 
TOLEDO, M. Os processos de modernização agrícola na região amazônica:

\section{Referências bibliográficas}

AMORIM, Antonia Terezinha dos Santos. Santarém uma síntese histórica. Santarém: Editora ULBRA, 1998.250p.

BECKER, Bertha. Amazônia: geopolítica na virada do terceiro milênio. Rio de Janeiro: Garamond, 2004.

BECKER, Bertha. Modernidade e gestão do território no Brasil: da integração nacional à integração competitiva. Espaço \& Debates, no $32,1991$.

BECKER, Bertha. Revisão das políticas de ocupação da Amazônia: é possível identificar modelos para projetar cenários? Parcerias Estratégicas, n. 12, 2001. pp. 135-159.

BRASIL EM AÇÃO. Lei no 9.276, de maio de 1996. PPA (1996 1999) -Diretrizes, objetivos e Metas. Brasília: Governo Federal, 1996.

BRASIL. O plano plurianual 1996-1999 (PPA 1996 -1997). Ministério do Planejamento, Orçamento e Gestão. Brasília, 1995.

BRASIL. O plano plurianual 2000-2003 (PPA 2000 -2003). Ministério do Planejamento, Orçamento e Gestão. Brasília, 1999.

CARVALHO, Inaiá Maria $M$. de. O Nordeste e o regime autoritário: discurso e prática do planejamento regional. São Paulo: HUCITEC- SUDENE, 1987.

CONAB. Safras - Grãos. Disponível em:< http://www.conab.gov.br/conabweb/index.php?PAG=131> Acesso em: 25 de julho de 2009.

CONSTITUIÇÃO DA REPÚBLICA FEDERATIVA DO BRASIL DE 1988. Constituição Federal de 1988. Brasília: Senado Federal/Presidência da República, 1988. 
TOLEDO, M. Os processos de modernização agrícola na região amazônica:

EMBRAPA. Programa Polonoroeste. Disponível em: <http://www.machadinho.cnpm.embrapa.br/conteudo/polono.html >. Acesso em: 30 de mar. 2009.

FLEXOR, Georges et. al. A expansão da cadeia da soja na Amazônia: Os casos do Pará e Amazonas. XLIV Congresso da Sociedade Brasileira de Economia e Sociologia Rural "Questões Agrárias, Educação no Campo e Desenvolvimento" Fortaleza, 23 a 27 de Julho de 2006. pp. 1-18.

HOMMA, Alfredo. O extrativismo do óleo pau-rosa na Amazônia. XLIII Congresso da SOBER "Instituições, Eficiência, Gestão e Contratos no Sistema Agroindustrial”. Ribeirão Preto, 24 a 27 de Julho de 2005. pp. 1-18.

LEÃO, Sandro A.V. Do Conselho Municipal de Desenvolvimento Rural à Implementação da Política de Desenvolvimento Territorial: Um Estudo a Partir de SantarémPa. 2006. 170 p. Dissertação (Mestrado em Desenvolvimento, Agricultura e Sociedade). Instituto de Ciências Humanas e Sociais. Universidade Federal Rural do Rio de Janeiro, RJ, 2006.

MACHADO, Lia Osório. Origens do Pensamento Geográfico no Brasil. Meio Tropical, Espaços Vazios e A Idéia de Ordem. CASTRO, Iná E. de; GOMES, P. C.; CORREA, R. L.. (Org.). Geografia: Conceitos e Temas, $1^{\text {a }}$ ed. Rio de janeiro: Betrand Brasil, 1995. pp. 309-353.

PREFEITURA MUNICIAL DE SANTARÉM. Coordenadoria Municipal de Desenvolvimento Urbano- CDU, Santarém, 2003.

PRODUÇÃO AGRÍCOLA MUNICIPAL (PAM) - IBGE. Séries Históricas - banco SIDRA. Disponível em: <http://www.sidra.ibge.gov.br/bda/tabela/listabl.asp?c=1612\&z=p $\& o=18>$. Acesso em 10 maio 2008. 
TOLEDO, M. Os processos de modernização agrícola na região amazônica:

SANTOS, Milton; SILVEIRA, María L. O Brasil: Território e Sociedade no início do século XXI. Rio de Janeiro: Record, 2001. 474p.

SPVEA - Superintendência do Plano de Valorização Econômica da Amazônia. SPVEA 1954/1960: política de desenvolvimento da Amazônia. Rio de Janeiro: SPVEA, 1960.

SPVEA - Superintendência do Plano de Valorização Econômica da Amazônia. Lei $\mathbf{n}^{\mathbf{0}} \mathbf{1 . 8 0 6}$, de 6 de janeiro de 1953. Rio de Janeiro: Imprensa Nacional, 1954.

THÉRY, Hervé. Situações da Amazônia no Brasil e no continente. Estudos Avançados. São Paulo. v. 19 (53), pp.37-49, 2005.

TOLEDO, Marcio. Circuitos espaciais da soja, da laranja e do cacau no Brasil: uma nota sobre o papel da Cargill no uso corporativo do território brasileiro. 2005. 156f. Dissertação (Mestrado em Geografia). Instituto de Geociências, Universidade Estadual de Campinas, Campinas, 2005.

Recebido em novembro de 2011 Aceito em junho de 2012 